\title{
OPTIMIZING ELEARNING DEVELOPMENT USING LEAN APPROACH
}

\author{
K. Lenin kumar $^{1}$
}

Abstract- The main focus of this journal is to discuss the opportunities of optimizing eLearning development by eliminating wastes using "muda" approach, thus by reducing the development cycle time by $20 \%$ and cost by $15 \%$. In lean approach, every step of development cycle to be revisited and wastes ("muda") in those steps will be identified. An alternate approach to achieve the same result will be suggested.

Keywords - Lean approach, eLearning optimization, muda, video based learning

\section{INTRODUCTION}

Learning is the act of acquiring new, or modifying and reinforcing existing, knowledge, behaviors, skills, values, or preferences which may lead to a potential change in synthesizing information, depth of the knowledge, attitude or behavior relative to the type and range of experience. Learning may occur consciously or without conscious awareness. Learning may occur as part of education, personal development, schooling, or training. It may be goaloriented and may be aided by motivation

\section{A. Why learning?}

We live and work in a changing world. New ideas and approaches emerge. New problems arise and new solutions are sought. The world of work is therefore a constantly moving and evolving one. New laws are introduced that lead to the introduction of new policies. This indicates that if we are not constantly learning as we go about our day-today business, then each day we are getting further and further out of touch with the demands of the modern working world.

It can be dangerous to get into a rut whereby we continue to carry out our duties in much the same way as we have done in the past. Expectations change over time and, if we do not adapt to the new circumstances, then we will be steadily more out of tune with what is required of us

Learning retention:

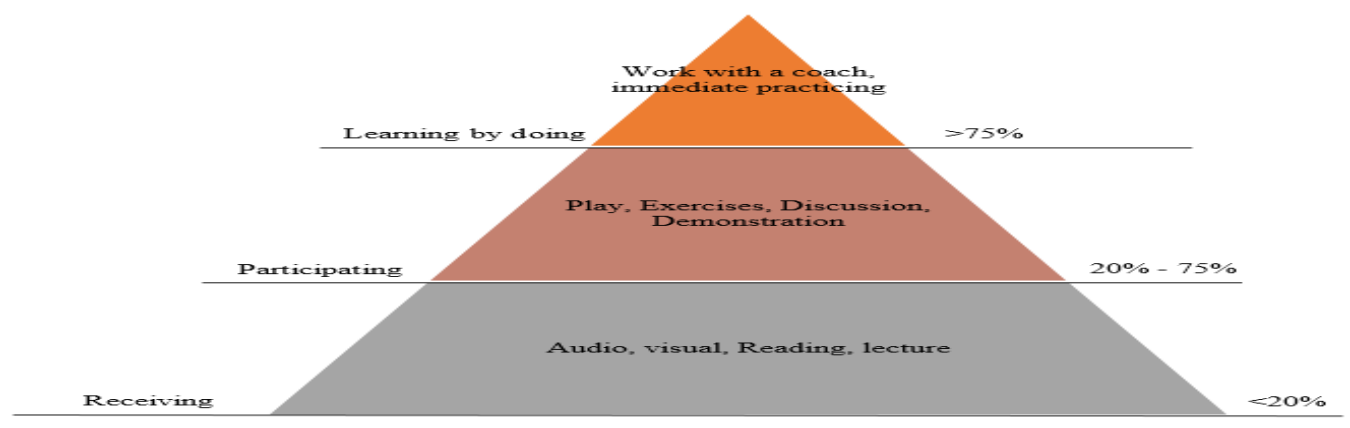

Figure 1 Learning retention

\footnotetext{
${ }^{1}$ Department of Industrial Engineering, Gnanamani College of Technology, Pachchal, Namakkal Dt. Tamil nadu, India
} 
In learning, as a first and important step is receiving. The learning happens less than $20 \%$ during this phase. By doing exercises, discussion and demonstration, the learning happens up to $75 \%$. After the learning, by putting the learning into practice more than $75 \%$ of the learning happens.

\section{TRADITIONAL LEARNING METHOD}

Learning is a continuous process. Every organization spend lot of money in training their employees. In traditional eLearning and trainer and trainee meet at a common place. The knowledge transfer happens via instruction, lecture, activity as individual or group activity. The trainer critically analyses the participant's response, analyses, evaluate and give feedback to them. After the training the participant goes back to their work and implement the learning.

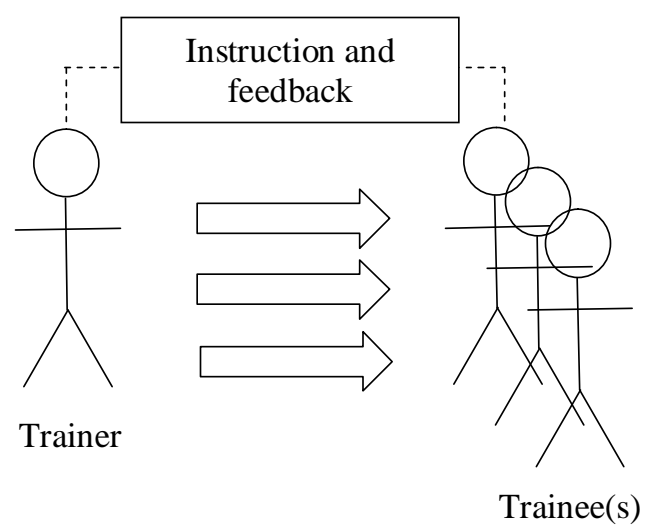

Figure 2 Traditional learning

A. $\quad$ Challenges in traditional learning:

- Expensive

- Time consuming

- Travel

- Having continuous guidance during implementation

- $\quad$ Some of the points may be discussable directly due to peer / boss presence in the same training

- $\quad$ Difficult to unlearn in quick span of time

- $\quad$ Engaging leaders

- Delivering consistent training

- Time commitment

\section{ELEARNING:}

Due to technology improvement and to reduce the cost, many organizations moved from traditional learning to virtual learning also called as video based learning or eLearning. e-learning is electronic learning, and typically this means using a computer to deliver part, or all of a course. This is delivered online, via the internet, via CD, DVD or tape. The technology improved to the extent that even direct interaction with the teacher via video conferencing also possible, now-a-days.

A. Benefits of eLearning:

- Convenient

- $\quad$ Flexible

- $\quad$ Can be tailored to different needs

- Immediate

- $\quad$ More cost effective

- Saves time without sacrificing quality

- Minimizes travel cost

- $\quad$ Better Suited for Geographically Diverse Employees

- $\quad$ Provides More Consistent Course Delivery

- Offer More Individualized Instruction 
B. $\quad$ Possible limitations of eLearning:

- $\quad$ It may be impersonal

- $\quad$ May not be suitable for all type of content

- $\quad$ Not everyone will feel comfortable to spend time in front of computer

- It requires self-discipline

- $\quad$ Possible lack of control

\section{TRADITIONAL ELEARNING DEVELOPMENT METHOD:}

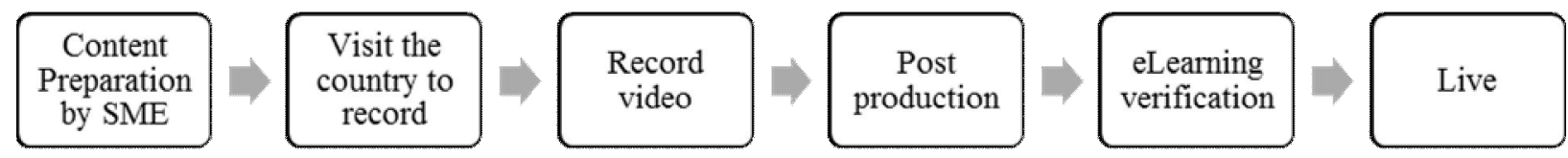

Figure 3 Traditional eLearning approach

1. As a first step the Subject Matter Expert (SME) who would give the presentation is identified and he / she prepares the presentation

2. Once, the presentation is ready, the eLearning development team, visit the SME's country with all the recording equipment.

3. The presentation gets records along with the presenter

4. Recorded presentation gets reviewed, any correction to be done gets rerecorded

5. Typically, the post production carried out in India due to cost advantage

6. The video that is converted into eLearning is shared to the SME for his review feedback

7. Based on the approval by SME, eLearning made available to live for all the employees in the organization

A. $\quad$ Timeline for typical eLearning

\begin{tabular}{|l|l|l|}
\hline S.No. & Description & Duration \\
\hline 1 & Content preparation & $3-4$ weeks \\
\hline 2 & Updating content after review (multiple iteration) & $2-3$ weeks \\
\hline 3 & Visa processing & $3-4$ weeks \\
\hline 4 & Video recording & 1 day \\
\hline 5 & Post production & 2 weeks \\
\hline 6 & Re-recording (if any, including waiting period) & 2 weeks \\
\hline 7 & Testing \& SCORM complaint & 1 week \\
\hline 8 & Pilot testing \& live & 2 days \\
\hline & Total duration & $14-16$ weeks \\
\hline
\end{tabular}

Table 1 Timeline for typical eLearning development

This journal discusses the options to optimize the eLearning development process by eliminating the wastes in each steps.

B. $\quad$ Seven wastes (muda)

1. Transport

2. Inventory

3. Motion

4. Waiting

5. Over production

6. $\quad$ Over processing

7. Defect

Transport:

Moving a product between manufacturing processes adds no value, is expensive and can cause damage or product deterioration. 
Inventory:

Parts on hand that customer has not purchased yet due to cycle time and lead time. Buffer stock used to offset variation in demand and production. Excess inventory ties up cash, creates extra handling, storage, and may never be recovered

Motion:

Excess motion that are done which is not part of standard way of working such as adjusting machine, frame a house, etc. are also considered as waste. The motion may cause unnecessary fatigue and long term injury. Proper ergonomics should be applied when making adjustment to motion studies.

Overproduction:

Building an excess quantity of units or more than the customer needs or is willing to pay for. This could be due to long set-up times, very long lead times, and difficulties known at start-up. This is often done to cover an underlying problem.

Waiting:

Processes are ineffective and time is wasted when one process waits to begin while another finishes. Instead, the flow of operations should be smooth and continuous. According to an estimate, as much as 99 percent of a product's time in manufacture is actually spent waiting.

Over processing:

The waste of excess processing that do not really add value to the customer, comes under over processing. This includes wastes such as over polishing parts, sorting parts that don't need to be sorted, heating parts at too long or too high of temperature, excessive washing, redundant paperwork, excessive data collection, tumbling, turning, drying parts longer than necessary and applying excess paint.

Defects:

Parts or units that do not meet the customer specification. Defects always require some degree of additional attention, whether it they are tracked, scrapped, reworked, or repaired. And these options may result in more waste or others of the seven wastes. Remember to consider all the confusion and delays that might have been associated with the scrap or rework

C. $\quad$ Wastes in typical eLearning development process

a) Content preparation:

Due to defective content (in sufficient information, content in incorrect format, etc), lot of time wasted in rework.

b) Visit to SME's location:

To record the course, a physical visit to the SME's country is carried out. This comes under transport waste.

c) Post production:

Post production is carried out by offshore team. In case of any issue found, they need to be re-recorded again. So, the onsite team, stays in the same country till the post production is complete. This comes under "waiting", "rework" and "defect" waste.

d) eLearning verification

After the post production, the eLearning is delivered to the SME for his final review. Any changes get re-recorded and the whole cycle gets repeated. There are, "Waiting" and "Rework" wastes in this step.

V. PROPOSED ELEARNING DEVELOPMENT METHOD:

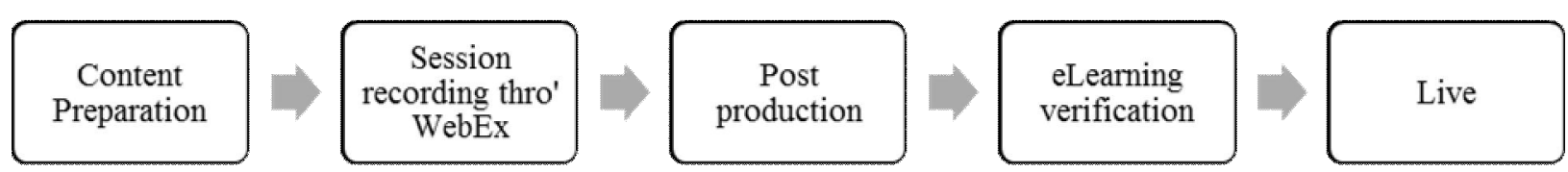

Figure 4 Proposed eLearning development method

A. Applying "muda" to eliminate waste

a) Content preparation 
Due to defective content (in sufficient information, content in incorrect format, etc), lot of time wasted in rework. A content preparation guideline document to be prepared to avoid this waste.

\section{b) Visit Country}

To record the course, a physical visit to the SME's country is carried out. This comes under transport waste. Instead of visiting the country physically, a WebEx session can be arranged to record the presentation explanation. All the audio can be recorded over telephone line.

\section{c) Post production}

Post production is carried out by offshore. In case of any issue found, they need to be re-recorded again. So, the onsite team, stays in the same country till the post production is complete. This comes under "waiting", "rework" and "defect" waste. By adopting WebEx session, this entire step can be eliminated

d) eLearning verification

After the post production, the eLearning is delivered to the SME for his final review. Any changes get re-recorded and the whole cycle gets repeated. There are, "Waiting" and "Rework" wastes in this step. This step can be optimized by implementing WebEx recording session as rework can be done much easier

B. Expected timeline:

\begin{tabular}{|l|l|l|}
\hline S.No. & Description & Duration \\
\hline 1 & Content preparation & $3-4$ weeks \\
\hline 2 & Updating content after review (multiple iteration) & 1 week \\
\hline 3 & Visa processing & - \\
\hline 4 & Video recording & 1 day \\
\hline 5 & Post production & 1 weeks \\
\hline 6 & Re-recording (if any, including waiting period) & 1 week \\
\hline 7 & Testing \& SCORM complaint & 1 week \\
\hline 8 & Pilot testing \& live & 2 days \\
\hline & Total duration & $10-12$ weeks \\
\hline
\end{tabular}

Table 2 Expected timeline based on new approach

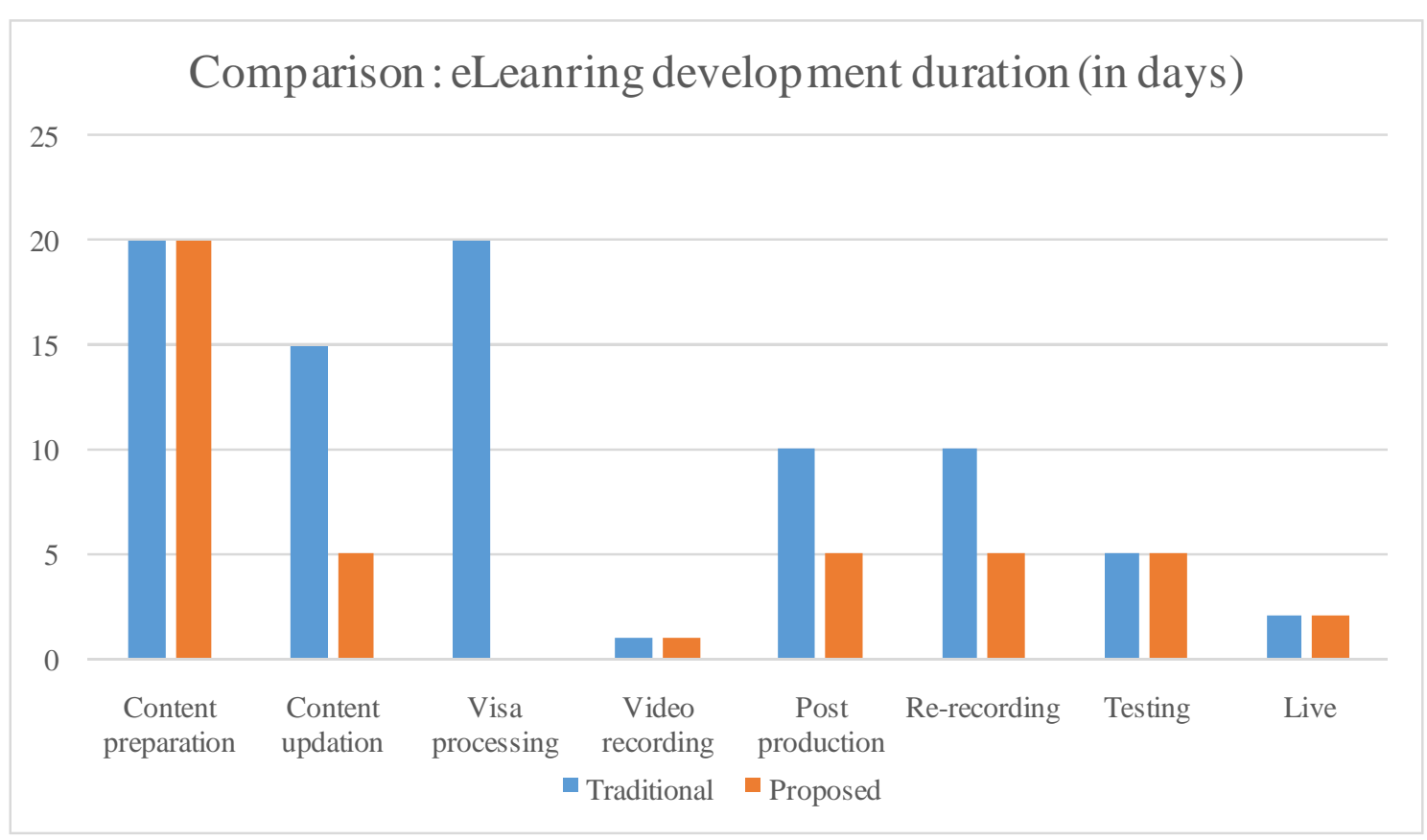

Figure 5 Duration comparison between old method and new method

The new approach would reduce the development cycle by $21 \%$

C. $\quad$ Expected cost benefit:

\begin{tabular}{|l|l|l|l|}
\hline S.No. & Description & Direct cost & Indirect cost* \\
\hline
\end{tabular}


Table 3 Expected cost benefit

\begin{tabular}{|l|l|l|l|}
\hline 1 & Content preparation & - & $30 \%$ \\
\hline 2 & Updating content after review (multiple iteration) & - & $20 \%$ \\
\hline 3 & Visa processing & $100 \%$ & - \\
\hline 4 & Video recording & $90 \%$ & - \\
\hline 5 & Post production & $40 \%$ & - \\
\hline 6 & Re-recording (if any, including waiting period) & $100 \%$ & - \\
\hline 7 & Testing \& SCORM complaint & - & $10 \%$ \\
\hline 8 & Pilot testing \& live & - & - \\
\hline & Average cost saving & $40 \%$ & $8 \%$ \\
\hline
\end{tabular}

*Indirect cost is calculated based on man-hour spend

The new approach would reduce the direct cost by $40 \%$ and indirect cost by $8 \%$

D. $\quad$ Expected benefits:

Direct:

- $\quad$ Reduced eLearning development cycle time

Indirect:

- $\quad$ Reduced final eLearning file size

- $\quad$ Decreased usage of bandwidth to access eLearning

- $\quad$ Reduced waiting time to load content in portal

- $\quad$ Faster completion of module due to quicker loading

- $\quad$ Participants will be more engaged due to quick loading and shorter completion time

\section{EXPERIMENT AND RESULT}

On experiment basis, a test module recorded using the proposed methodology.

1. A two page eLearning creation guidance document created and circulated to Subject Matter Expert. The content was checked before the recording session by eLearning experts.

2. A mock-up recording session conducted prior to live recording session

3. Live recording conducted through webEx for video along with animation

4. All the audio parts were recorded using professional audio recorder

5. The transcript was created by medical transcription experts

6. $\quad$ Flash based visual was created off-line using the recorded video

7. Audio part was created using professional voice artist

8. The video and audio were synced and eLearning created

9. The eLearning sent to SME for verification and validation

A. $\quad$ Recorded observation (duration):

\begin{tabular}{|l|l|l|l|}
\hline S.No. & Description & $\begin{array}{l}\text { Expected } \\
\text { duration* }\end{array}$ & Actual duration \\
\hline 1 & Content preparation & 20 & 20 \\
\hline 2 & Updating content after review (multiple iteration) & 5 & 3 \\
\hline 3 & Video recording & 1 & 1 \\
\hline 4 & Post production & 5 & 7 \\
\hline 5 & Re-recording (if any, including waiting period) & 5 & 5 \\
\hline 6 & Testing \& SCORM complaint & 5 & 4 \\
\hline 7 & Pilot testing \& live & 2 & 2 \\
\hline & Total & 43 & 42 \\
\hline
\end{tabular}

Table 4 Recorded duration

*Based on worst case scenario (in days) 


\section{IV.CONCLUSION}

The experiment results are promising, even though few challenges found, such as creating transcript from recorded voice, content changed by SME after recording. But these can be over-come in future by having right quality assurance in place. The proposed method brought down the direct eLearning creation cost by $40 \%$ and reduced the time frame for development by $21 \%$

\section{REFERENCES}

[1] Diane L King, David I Ben-Toviam and Jane Bassham, "Redesigning emergency department patient flows: Application Lean thinking to heath care", Journal notes in Management and Quality, pp. 392-393, 2006

[2] Irene L Vegting, Marlou van Beneden, mark HH Kramer, Abel Thijs, Piet J Kostense, Prabath WB Nanayakkara, "How to ave costs by reducing unnecessary testing: Lean thinking in clinical practice", Journal in European Journal of Internal medicine 23(2012), pp. 2, 2012

[3] Pergamon, "Lean thinking review", European Journal of purchasing \& supply chain management, pp 241 242,1997

[4] Bob Carroll, "Leadership in Lean, Empowering Manufacturing Organizations", Journal of organisational excellence, pp 83-84, Spring 2001

[5] Jose Moyano-Fuentes, Macarena Sacristan-Diaz, "Learning on lean: a review of thinking and research", International Journal of Operations \& Production Management, pp551-582, 2011

[6] Fawaz A. Abdulmalek, Jayant Rajgopal, "Analyzing the benefits of lean manufacturing and value stream mapping via simulations: A process sector case study", International journal of production economics, November 2006

[7] Arnout Pool, Jacob Wijngaard n, Durk-Jouke van der Zee, "Lean planning in the semi-process industry, a case study", International journal of production economics, June 2006

[8] Kai Petersen, Claes Wohlin, "Software process improvement through the Lean Measurement (SPI-LEAM) method", The Journal of Systems and Software 83 (2010) 1275-1287, February 2010 